\title{
ALTERNATIVE METHOD FOR QUALIFICATIONS OF GLASS FIBRE REINFORCED EPOXY PIPES (GRE)
}

\author{
Tarak Assaleh ${ }^{1}$, Siddig Dabbashi ${ }^{2}$, and Asya A. Gabbasa ${ }^{3}$ \\ ${ }^{1,2}$ Faculty of Engineering, Sabratha University. \\ ${ }^{3}$ Faculty of Engineering, Zawia University.
}

\begin{abstract}
This paper discusses the Ultimate Elastic Wall Stress (UEWS) test for GRE pipes under pure hydrostatic loading. UEWS appears to provide an attractive alternative to the currently used procedure laid down in ISO 14692, which involves an expensive series of long term constant pressure tests, as described in ASTM 2992, running for a period in excess of 10,000 hours.
\end{abstract}

The pipes were subjected to biaxial loading, which was attained by combinations of hoop and axial stress. Loads were applied as groups of cycles which, were gradually increased until the UEWS had been determined. UEWS test has proved to be one of the most effective in terms of accuracy and speed. Moreover, it has been found to be sensitive to changes in key manufacturing and raw material parameters.

Modelling results are also showed a harmonic approach and accepted to that obtained experimentally. This encourages to apply the proposed modelling for further biaxial load ratios.

\section{Introduction}

Most of Infrastructure applications and piping systems require material solutions that have a competitive cost and satisfied strength. Filament wound glass fibre reinforced epoxy (GRE) pipes are being increasingly used in a wide range of applications, such as high pressure containers in the petrochemical and oil industries due to their superior corrosion resistance and high strength to weight ratio Jinbo Bai and et.al (1997). This has encouraged researchers to carry out and develop experimental and theoretical investigations in order to understand their mechanical and failure behaviour under a variety of loading conditions Garret Meijer (2008). It has been proven that the mechanical properties of composites are critically influenced by environmental factors, where the fibre-matrix interface becomes highly degraded. This degradation is also known to intensify under elevated temperatures Soykok Ibrahim and et.al (2013).

The research is being carried out against a background of a review of qualification procedures described in ISO 14692. Fiberglass pipe, notably glass reinforced epoxy (GRE) pipe, is used 
in the energy industries where corrosion resistance is required Gibson, A.G and etal (2010). The pipes referred to here are manufactured by filament winding, which produces a multi-layer laminate with plies aligned at $\pm 55^{\circ}$ to the axial direction.

Pipes failed when Weepage occurred and drops of liquid are penetrate the pipe wall, weepage accurse when the concentration or density of cracks reaches a level where a fluid path is possible through the pipe wall

\section{Failure Regression Lines}

Currently, the ISO 14692 standard is used to predict the maximum service pressure for GRE pipes. The standard describes the method used to establish the regression line to predict long term allowable stress. This method is based on pressurising the GRE pipes statically or cyclically to derive at least 18 points in order to establish an acceptable regression line, with at least one sample providing a point in excess of 10,000 hours. A graph with log-log format is plotted in terms of stress versus time to failure. By extrapolating the lower confidence limit (LCL) from the regression line, the rating for a design lifetime of 20 years can be obtained as in figure 1. The expected failure mode of this test is weepage, which is generally due to the presence of a network of matrix cracks which form over time ISO14692-2 (2002). The regression line obtained from this procedure gives important information that qualifies the product for manufacture and defines the pressure rating to be used in the pipe's system design.
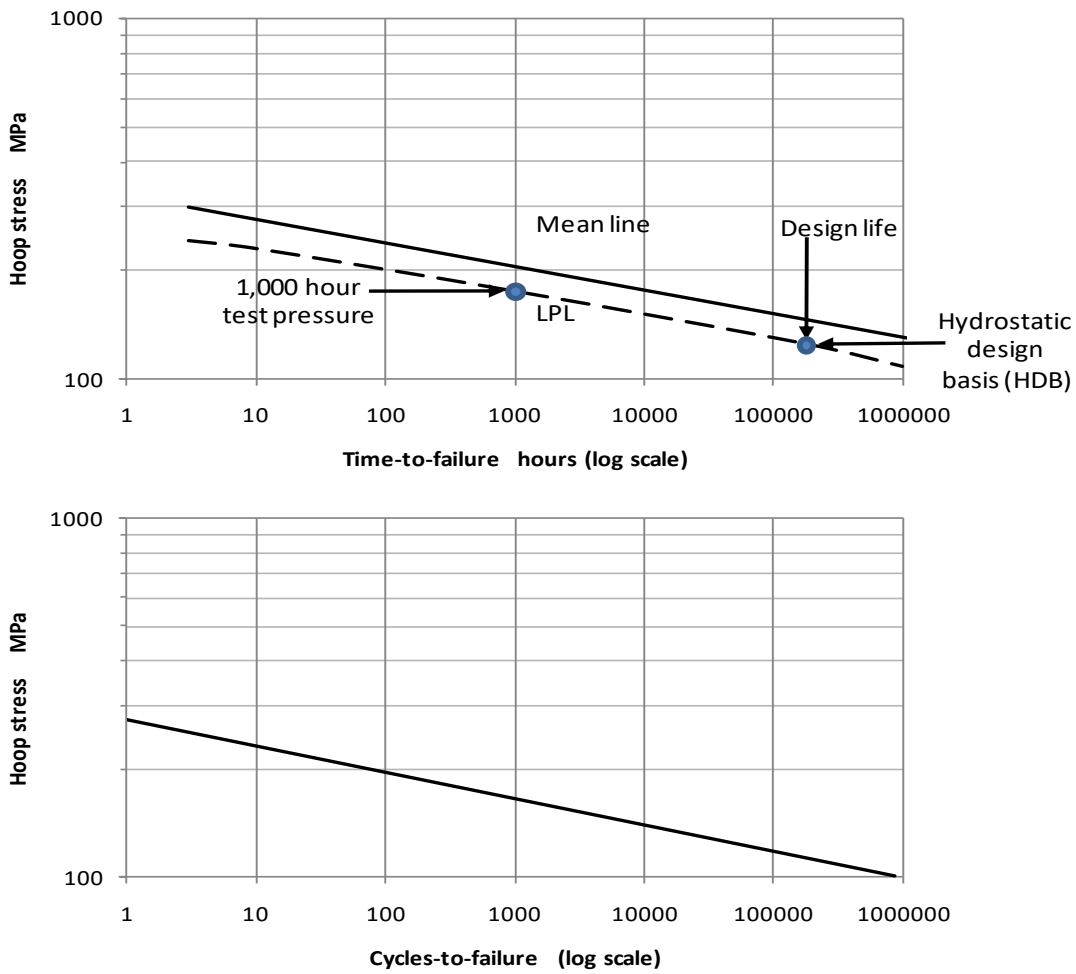

Figure (1): Static (Upper) and Cyclic (Lower) Test Results at $65^{\circ} \mathrm{C}$ from ISO 14692 and ASTM 2992. 
The hydrostatic design basis (HDB) is a method used for the reconfirmation of the product using a regression line built from ASTM D2992. This is needed when any change is made to materials, manufacturing processes, construction, and liner thickness or fitting design. In the HDB test, the product is subjected to 1,000 hours of hydrostatic pressure based on the 1,000 hour lower prediction limit (LPL) of the regression line obtained from ASTM D2992. If there is no weepage or bursting at 1,000 hours, this means that the product is considered safe for the same design lifetime of 20 years ISO14692-2 (2002)

\section{Experimental Method}

The UEWS tests were implemented on fibre glass pipes of $200 \mathrm{~mm}$ diameter, 2 meters pipe length and wall thickness of $6 \mathrm{~mm}$. The pipes were subjected to pure hydrostatic groups of pressure started with a nominal pressure $\left(P_{N}\right)$, which was determined, as well as the design load condition as shown in Figure (2).

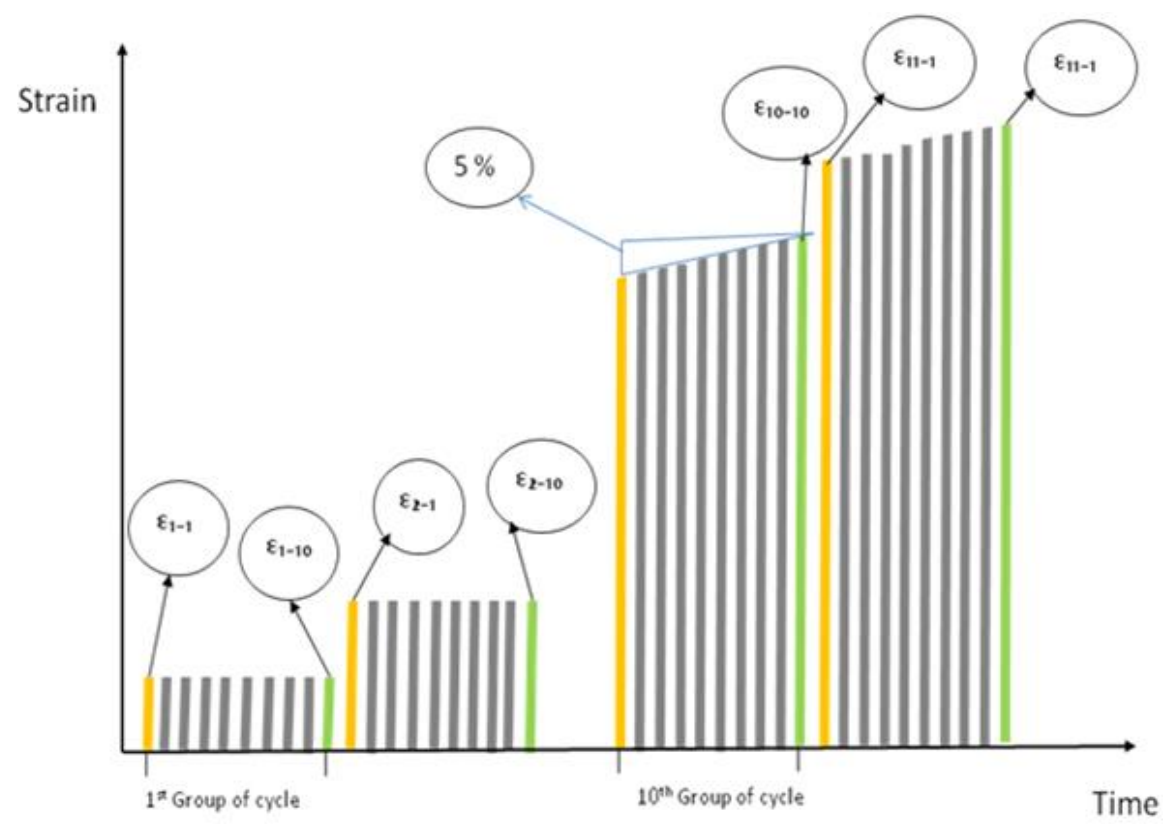

Figure (2): Definition of Test Cycles and Cycle Groups.

Secondly, the cycle test pressure (CTP) was determined, starting at $10 \%$ of the expected UEWS as follows:

$$
C T P_{1}=0.1 * P_{U E W S} \exp .
$$

The pipe was then filled completely with drinking water, an air driven pump was then attached to the system with pressure gauge. A strain gauges were also attached to the pipe in axial and hoop directions. The first cycle test pressure was applied with pressure increment from zero to the $C T P_{1}$ of wall stress of $5-10 \mathrm{MPa} /$ minute. Ten cycles were applied under $C T P_{1}$ holding for 
one minute at the each given pressure and one minute at conditions of zero pressure. This showed a compensation of static and cyclic loading applied synchronously to the pipe wall.

The pressure was then uniformly increased to the second group of cycles, which can be determined by adding $10 \%$ of the expected UEWS as follows:

$$
C T P_{i+1}=C T P_{i}+0.1 * P_{U E W S} \exp .
$$

where: $C T P_{i}$ is the cycle test pressure of the current group (MPa), $C T P_{i+1}$ is the next cycle group of ten cycles $(\mathrm{MPa})$, and $P_{U E W S}$ exp. is the test pressure corresponding to the expected UEWS (MPa). The procedure was repeated until one of the follow conditions has been satisfied:

- Weeping or failure of the pipe.

- The completion of two cycle groups after the UEWS point.

Strain measurements as well as pressure readings were taken at the end of the first and tenth cycles. The UEWS was investigated when the difference in strains between the $1^{\text {st }}$ and $10^{\text {th }}$ cycles of the same cycle group exceeds $5 \%$.

$$
\varepsilon_{10 i} / \varepsilon_{1 i}>1.05
$$

where: $\varepsilon_{1 i}, \varepsilon_{10 i}$ are the strains at the end of the first and tenth cycles respectively. The test was continued for two cycle groups after the UEWS point using the same procedure.

\section{Modelling Methods}

All the pipes were geometrically similar with dimensions mentioned above. Pipes were built with winding angle of $\pm 55^{\circ}$. This angle is commonly encountered because Netting analysis suggests that this is the best angle to use in piping system where the ratio of applied hoop to axial stress is 2:1, D.Hull and T.W. Clyne (1996). The parameters were used to evaluate the elastic and shear modulus of the pipe are listed in the below table:

Table (1): Physical and mechanical properties of the pip.

\begin{tabular}{|c|c|c|}
\hline Materials & Test method & \\
\hline Epoxy Density & & $1.8 \mathrm{~g} / \mathrm{ml}$ \\
\hline Volume fraction (\%) & & $59 \%$ \\
\hline Axial Young's modulus (Ex) & ASTM D 2105 & $12 \mathrm{GPa}$ \\
\hline Axial strength & ASTM D 2105 & $75 \mathrm{MPa}$ \\
\hline Hoop Young's modulus (Ey) & ASTM D 2290 & $20 \mathrm{GPa}$ \\
\hline Hoop strength & ASTM D 2290 & $210 \mathrm{MPa}$ \\
\hline Shear modulus (Es) & & $11.5 \mathrm{GPa}$ \\
\hline Thermal conductivity & & $0.29 \mathrm{~W} / \mathrm{m} . \mathrm{K}$ \\
\hline Poisson ratio axial/hoop & $N_{x y}$ & 0.65 \\
\hline Poisson ratio hoop/axial & $N_{y x}$ & 0.38 \\
\hline
\end{tabular}


The engineering elastic constants were calculated from the Halpin-Tsai equations by:

$$
\begin{gathered}
E_{11}=E_{f} V_{f}+E_{m} V_{m} \quad \text { (4) , } \quad E_{22}=E_{m} \frac{\left(1+\xi_{e} \eta_{e} V_{f}\right)}{\left(1-\eta_{e} V_{f}\right)} \\
v_{12}=v_{f} V_{f}+v_{m} V_{m} \\
\eta_{e}=\frac{(6)}{\left(\frac{E_{f}}{E_{m}}+\xi_{e}\right)} \quad \text { (8) }, \quad G_{12} \frac{\left(1+\xi_{s} \eta_{s} V_{f}\right)}{\left(1-\eta_{s} V_{f}\right)} \\
v_{21}=\left(V_{f} v_{f}+V_{m} v_{m}\right) \frac{E_{22}}{E_{11}}=\frac{\left(\frac{G_{f}}{G_{m}}-1\right)}{\left(\frac{G_{f}}{G_{m}}+\xi_{s}\right)}
\end{gathered}
$$

Where:

$E_{f}, E_{m}:$ Fiber and matrix elastic modulus respectively.

,$V_{f}$ : Fibre volume fraction.

$v_{f}, v_{m}:$ Poisson ratios of fibre and matrix

Since UEWS procedure considering both the cyclic and static failure, therfore processes can be described by empirical power law expressions:

$$
\sigma=H N_{f}^{-J} \quad \text { and } \quad \sigma=F t_{f}^{-G}
$$

Where:

$\sigma:$ Hydrostatic pressure.

$\mathrm{N}_{\mathrm{f}}$ : Number cycles.

$t_{f}:$ Number cycles.

H, J, F and G : Material constants.

By referring to Miner's Law summation, which expressed that damage occurred as a result of a cumulative damage of either static or cyclic loading. In this study the novelty is to use the Miner's Law in static and cyclic load in the same time. So this can be expressed as: 


$$
\sum \frac{\sigma_{i} t_{i}}{t_{i f}}+\sum \frac{\sigma_{i} N_{i}}{N_{i f}}=1
$$

Where:

$\mathrm{N}_{\mathrm{i}}$ : Number of cycle up to failure.

$\mathrm{t}_{\mathrm{i}}$ : Time to failure under static loading.

By modifying equation (11), $\mathrm{N}_{\mathrm{f}}, \mathrm{t}_{\mathrm{f}}$ can be expressed as:

$$
N_{f}=\left(\frac{\sigma}{H}\right)^{-\frac{1}{J}} \quad \text { and } \quad t_{f}=\left(\frac{\sigma}{F}\right)^{-\frac{1}{G}}
$$

This can be now applied for UEWS test, which considered of Appling of 10 cycles for the giving load and holding for one minute as previously discussed. this can confidently expressed as:

$$
\frac{10}{60} F^{-\frac{1}{G}}\left(\sigma^{\frac{1}{G}}+(2 \sigma)^{\frac{1}{G}}+(3 \sigma)^{\frac{1}{G}}+\ldots \ldots .\right)+10 H^{-\frac{1}{J}}\left(\sigma^{\frac{1}{J}}+(2 \sigma)^{\frac{1}{J}}+(3 \sigma)^{\frac{1}{J}}+\ldots \ldots\right)=1
$$

\section{Results and Discussion}

Figure 3 shows the results obtained from UEWS test, hoop stress versus axial strain were fitted for $1^{\text {st }}$ and $10^{\text {th }}$ cyclic loading respectively. A noticeable deviation between the $1^{\text {st }}$ and $10^{\text {th }}$ cycles started at hope stress of $170 \mathrm{MPa}$. At this level equation 3 was satisfied and two extra groups were implemented up to pipe failure by weppage. 


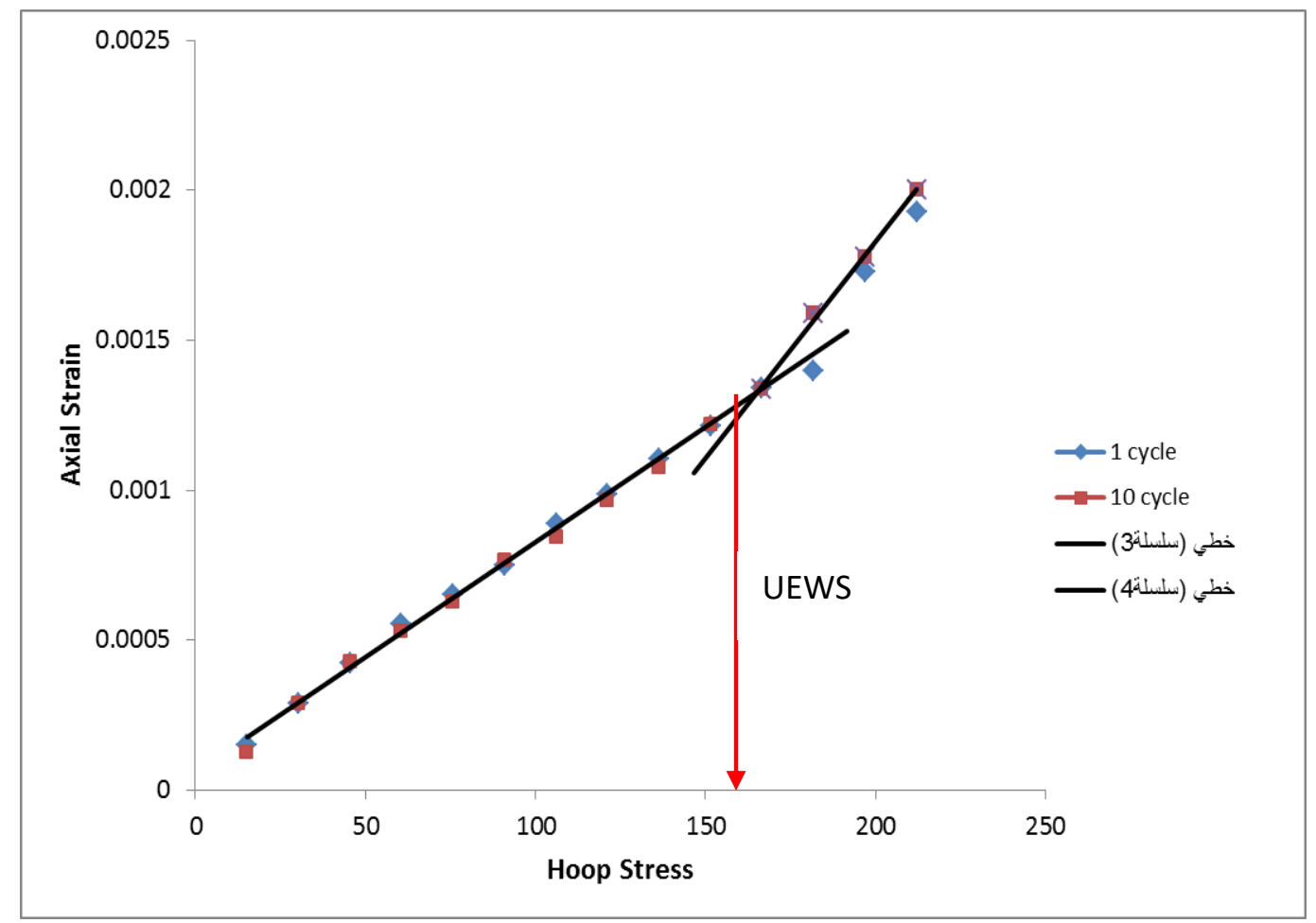

Figure (3): UEWS Test for GRP Pipe

Figure 4 shows the application of Miner's Law in UEWS test, significant influence of the cyclic loading is apparently exceeds the contribution from static fatigue. The contribution were to implement the UEWS test in few hours comparing with the current used ASTM2992b, which exceeds 10,000 hours.

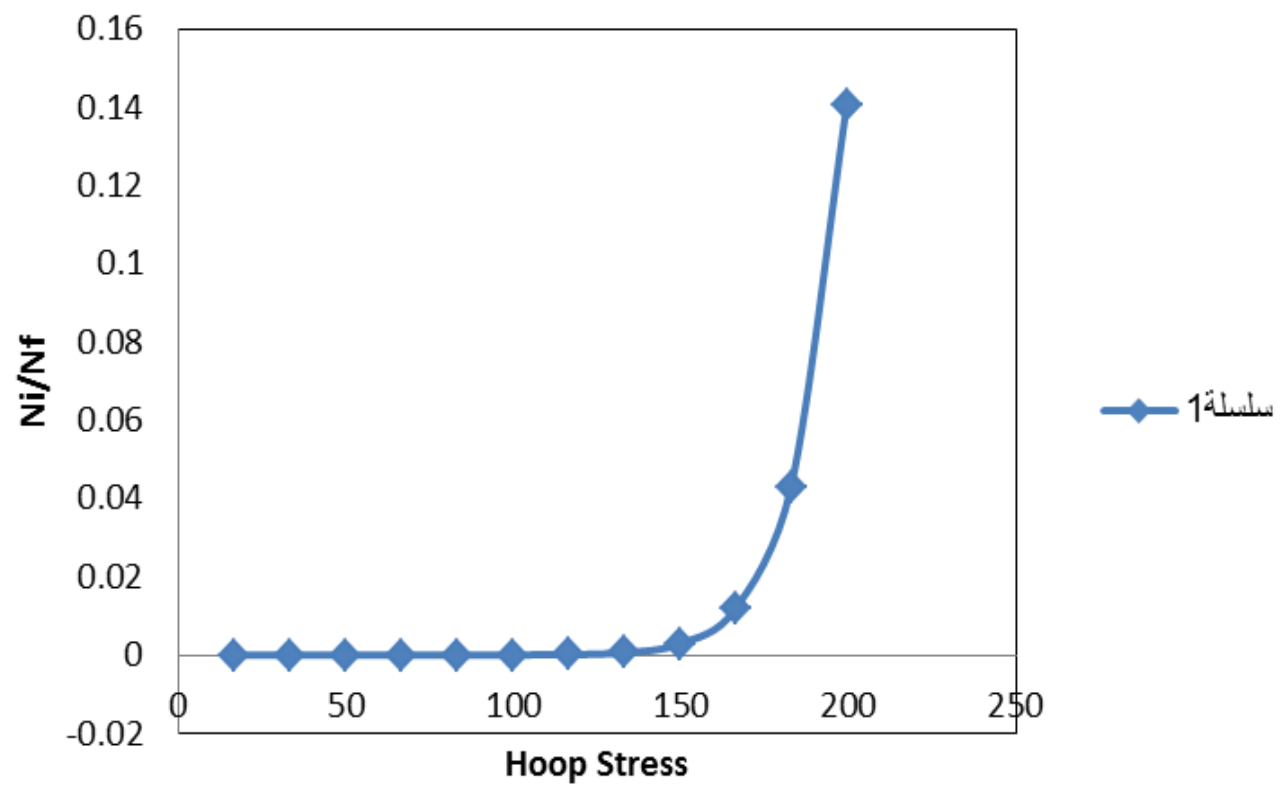

Figure (4) Miner's Law Sum for Hoop Stress in UEWS Test. 
Miner's Law Sum also appears to realise the changing in elastic constants during the design life in UEWS test. Results showed a harmonic approach and accepted to that obtained from UEWS test as in figure 5.

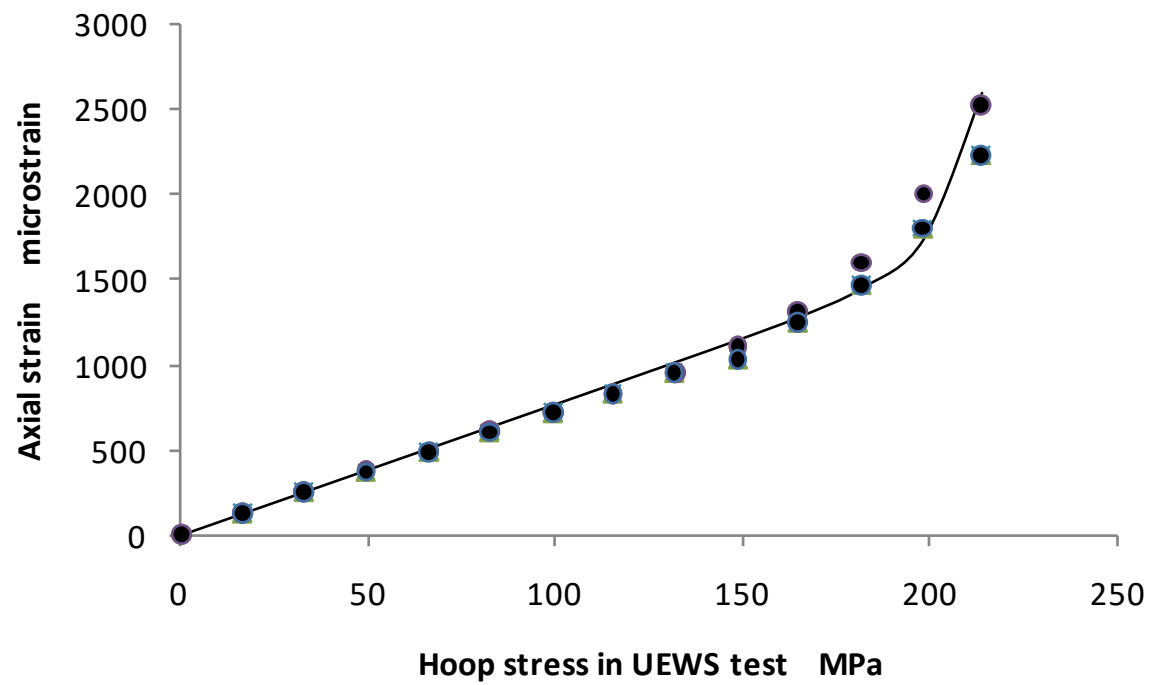

Figure 6. Miner's Law Sum Approach to UEWS Test.

\section{Conclusion and Recommendations}

UEWS test appears to be an attractive method for GRE pipe qualification among the currently used methods. Durable stress for the specified glass reinforced epoxy pipes was $170 \mathrm{MPa}$, therefore, this gives an idea for the limitation use of such pipes.

The harmony results of the proposed modelling encouraging to be applied for different pipe specifications and load conditions, this could provide an alternative procedures to experimental UEWS tests, which at least consumed materials and time.

Strongly recommend for future work that UEWS test and modelling to be for carried out different temperature, as GRE pipes showed a sensitive to the media temperature.

\section{References}

- Jinbo Bai, G.H., Mechanical behaviour of $\pm 55^{\circ}$ filament wound glass-fibre/epoxy-resin tubes: II Micromechanical model of damage initiation and the competition between different mechanisms. Composites Science and Technology, 1997. 57: p. 155-164.

- Garret Meijer and F. Ellyin, A failure envelope for $\pm 60^{\circ}$ filament wound glass fibre reinforced epoxy tubulars. composites part A: applied science and manufacturing, 2008. 39: p. 555-564. 
- Soykok Ibrahim Fadil, Sayman Onur, Pasinli Ahmet. Effects of hot water aging on failure behaviour of mechanically fastened glass fibre/epoxy composite joints. Composites Part B 2013;54: 59-70

- Gibson, A.G., M.S. Abdul Majid, T.A. Assaleh and J.M. Hale, Qualification and Test Procedures for Fiberglass Pipe for Oil and Gas Applications, Middle East Corrosion Conference, Bahrain, 2010.

- ISO14692-2:2002, Petroleum and natural gas industries: Glass-reinforced plastics (GRP) piping. 2002.

- D.Hull and T.W. Clyne, An introduction of composite materials. Cambridge University Press, 1996. 2nd edition. 